\title{
ESTRUCTURA COMUNITARIA DEL FITOPLANCTON DE LA CUENCA PACÍFICA COLOMBIANA DURANTE LA CAMPAÑA OCEANOGRÁFICA PACÍFICO XXXIX-ERFEN XXXVII
}

\author{
Diego Germán Ramírez ${ }^{1}$ \\ Alan Giraldo López ${ }^{1}$ y 2 \\ ${ }^{1}$ Departamento de Biología,Universidad del Valle, Calle 13 No. 100 - 00, Edif. 320, Oficina 3118, \\ Cali, Valle, Colombia e-mail: oceanografia@univalle.edu.co \\ ${ }^{2}$ Grupo de Investigación en Estudios Oceanográficos y del Fenómeno El Niño, \\ Centro Control Contaminación del Pacífico (CCCP), Vía El Morro, Capitanía de Puerto, \\ San Andrés de Tumaco, Nariño, Colombia e-mail: oceanografia@univalle.edu.co
}

Ramírez, D. y A. Giraldo. 2006. Estructura comunitaria del fitoplancton de la Cuenca Pacífica Colombiana durante la campaña oceanográfica PACÍFICO XXXIX-ERFEN XXXVII. Boletín Científico CCCP, (13): 65-84.

\section{Recibido en marzo de 2006; aceptado en diciembre de 2006}

NOTAACLARATORIA: Este documento hace parte del proyecto de investigación titulado 'Producción primaria, biomasaza fitoplanctónica y composición taxonómica del fitoplancton y zooplancton del Pacífico colombiano: una aproximación holística a la base del sistema pelágico, Cl:7662', a favor de A. Giraldo, financiado parcialmente por el Centro Control Contaminación del Pacífico, CCCP, la Dirección General Marítima, DIMAR, y la Universidad del Valle.

\section{RESUMEN}

Se estudió la composición, diversidad, biomasa y estructura taxonómica del fitoplancton en el Pacífico colombiano durante la campaña oceanográfica PACÍFICO XXXIX-ERFEN XXXVII. Se siguió un plan operativo de 40 estaciones de muestreo ubicadas equiespaciadamente a través del océano Pacífico colombiano. Se realizaron muestreos discretos de fitoplancton

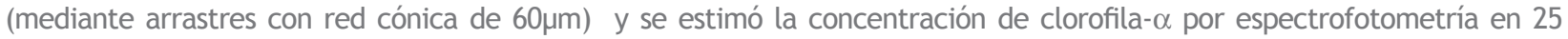
estaciones de muestreo. Se identificaron 126 morfoespecies de fitoplancton, pertenecientes a 37 géneros. Se observó una amplia dominancia de los géneros de diatomeas: Chaetoceros, Coscinodiscus, Thalassionema, Bacteriastrum, Rhizosolenia, Ditylum, Skeletonema, Nitzschia y Pseudonitzschia, seguidas por los géneros de dinoflagelados: Ceratium, Ornithocercus, Pyrophacus, Protoperidinium, Dinophysis, Ceratocorys, Gonyaulax, Podolampas y Amphisolenia, que aumentaron su presencia en la zona oceánica. La concentración de clorofila- $\alpha$ fue homogénea en la zona de estudio con valores entre $11.37 \mathrm{mgm}^{-2}$ y $38.05 \mathrm{mgm}^{-2}$ (valor integrado zona de influencia friccional: 0 a 50m), destacándose dos centros de alta concentración en el sector norte de la cuenca: uno en la zona oceánica (Estación 75) y otro en la zona costera (Estación 12). Los índices de diversidad de Shannon-Wiener $\left(\mathrm{H}^{\prime}\right)$ y de riqueza o números de Hill $\left(\mathrm{N}_{0}\right.$ y $\left.\mathrm{N}_{1}\right)$ fueron mayores en promedio en la zona costera.

PALABRAS CLAVE: fitoplancton, diatomeas, dinoflagelados, ERFEN, Pacífico colombiano, taxonomía, oceanografía biológica, clorofila- $\alpha$.

\section{ABSTRACT}

Biomass, diversity, composition and taxonomic structure of phytoplankton in the Pacific Ocean of Colombia were studied during Pacific XXXIX-ERFEN XXXVII oceanographic survey. The operative plan of sampling was structured along 40 stations in the Pacific Ocean of Colombia. Discrete sampling of phytoplankton was carried out by oblique trawling with standard phytoplankton net $(60 \mu \mathrm{m})$ in the 25 biological stations. Furthermore, chlorophyll-a concentration at standard depth in each biological stations were estimated by spectrophotometry technique. 126 morph species of phytoplankton, belong to 37 genera, were identified. The Diatom's genera: Chaetoceros, Coscinodiscus, Thalassionema, Bacteriastrum, Rhizosolenia, Ditylum, Skeletonema, Nitzschia and Pseudonitzschia, were the dominant, following by Dynoflagelate's genera: Ceratium, Ornithocercus, Pyrophacus, Protoperidinium, Dinophysis, Ceratocorys, Gonyaulax, Podolampas and Amphisolenia. This last taxonomic group trend to increase their abundance in the oceanic zone. Chlorophyll-a concentration was homogenous in the study area, ranged between $11.37 \mathrm{mgm}^{-2}$ to $38.05 \mathrm{mgm}^{-2}$ (integrate from 50 to $0 \mathrm{~m}$ ). Moreover, two centers of high Chlo-a concentration were identified: one in the northern sector of oceanic zone (station 75) and the other one in the northern sector of coastal zone (Station 12). Diversity index of Shannon ( $\left.\mathrm{H}^{\prime}\right)$ and richness of Hill's numbers $\left(\mathrm{N}_{0}\right.$ y N $\left.\mathrm{N}_{1}\right)$ were higher in costal zone that oceanic zone.

KEY WORDS: phytoplankton, diatoms, dinoflagellate, ERFEN, Pacific Ocean, phytoplankton taxonomy, biological oceanography, chlorophyll- $\alpha$. 


\section{INTRODUCCIÓN}

El plancton es el conjunto de organismos (bacterias, vegetales y animales) adultos y larvarios que viven suspendidos en el agua, con independencia del fondo, y debido a un limitado sistema de locomoción acompañan pasivamente el movimiento de las masas de agua (Lalli y Parsons, 1997). Este término fue utilizado por primera vez por Víctor Hensen en 1887, quien denominó como fitoplancton al componente vegetal del plancton; el cual está conformado por algas unicelulares (excepcionalmente multicelulares) que pueden ser solitarias o coloniales, mientras que el componente animal fue denominado zooplancton, el cual dependiendo del tamaño puede ser clasificado como picoplancton $(<20 \mu \mathrm{m})$, microplancton (entre $20 \mu \mathrm{m}$ y $200 \mu \mathrm{m}$ ) o mesoplancton

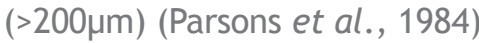

La distribución biogeográfica de los organismos del plancton es discontinua y está determinada principalmente por la temperatura y la salinidad, que son irregulares entre la superficie y los $150 \mathrm{~m}$, pero que se hacen más estables a partir de $200 \mathrm{~m}$ de profundidad (Johnson y Allen, 2005). Sin embargo, el fitoplancton requiere de las condiciones de luminosidad óptima cercanas a la superficie de la columna de agua, por lo que su distribución vertical generalmente está asociada a una zona subsuperficial. En ambientes costeros y oceánicos, el fitoplancton consume rápidamente los nutrientes disponibles en la parte superficial de la columna agua, por lo que su distribución espacial estaría estrechamente asociada a la disponibilidad de nutrientes, elementos que son aportados desde el continente por escorrentía o desde la parte profunda de la columna de agua por surgencia (Mann y Lazier 1996)

Los organismos fitoplanctónicos son autótrofos, poseen pigmentos fotosintéticos que les permiten fijar la energía solar por fotosíntesis usando dióxido de carbono, nutrientes y metales traza (Mann, 2000). En este contexto, el fitoplancton, como grupo fotosintetizador es productor primario, es decir que forma la etapa inicial del proceso de producción de materia orgánica y ocupa el lugar base dentro de la cadena trófica. Su importancia ecológica radica en que comprende la mayor porción de organismos productores primarios en el océano y es, como las plantas en la Tierra, el alimento básico para los consumidores como el zooplancton y los peces (Parsons et al., 1984; Miller, 2004). Al ser comparado con otros productores primarios del mar como las fanerógamas y las algas marinas, el fitoplancton resulta ser, por mucho, la parte fundamental de la producción en el mar. Aunque la gran unión de algas macroscópicas y plantas ancladas puede ser responsable de un desarrollo considerable de la producción en algunas aguas someras, su contribución a la productividad total del mar es probablemente insignificante si se le compara con el aporte fitoplanctónico (Dawes, 1991; Nybaken, 1997; Barnes y Hughes, 1999)

El estudio de los productores primarios en muchos casos resulta explicativo de muchos de los fenómenos que se dan en niveles superiores de la cadena energética. En tal sentido, la relevancia de los estudios sobre fitoplancton se incrementa por ser el primer eslabón de la cadena trófica marina, lo que determina la riqueza de la comunidad pelágica que directa o indirectamente se alimenta de él. En este contexto los estudios sobre el fitoplancton, más allá del interés científico que suscitan, resultan de importancia primordial en el conocimiento de la potencialidad de un área, para mantener una comunidad de nivel trófico superior, económicamente explotable.

Conel presente estudiose aporta conocimiento detallado sobre la estructura, composición y distribución espacial del componente fitoplanctónico en el océano Pacífico colombiano, insumo básico necesario para realizar una aproximación holística a la base del sistema pelágico.

\section{ÁREA DE ESTUDIO}

La cuenca del Pacífico colombiano, CPC, tiene $80000 \mathrm{~km} 2$ de superficie y se ubica sobre la costa occidental de Colombia. Se encuentra dentro de la región de bajas presiones atmosféricas, conocida como concavidad ecuatorial de bajas presiones, donde convergen los vientos alisios de cada hemisferio para formar la zona de convergencia intertropical, ZCIT. Aquí convergen masas de aire con diferencias térmicas y gradientes de humedad, las cuales ascienden en forma de banda nubosa por los procesos de convección, caracterizando esta zona por vientos variables y débiles (zona de calmas ecuatoriales) y por una alta pluviosidad. El clima es superhúmedo, con promedio de precipitación en la zona litoral entre 3000 y $5000 \mathrm{~mm}^{3} \mathrm{anno}^{-1}$, y un arrastre promedio de sedimentos de $350 \times 10^{6} \mathrm{~m}^{3} \mathrm{año}^{-1}$ (Forsberg, 
1969; Prahl et al., 1990). En el sector costero predomina la corriente de Colombia que se dirige de norte a noreste, presentando su mayor intensidad en Cabo Manglares y Punta de Coco, interactuando con la corriente del Chocó que se desplaza a lo largo de la costa hacia el sur (Andrade, 1992; RodríguezRubio et al., 2003)

El área de estudio se localizó en la zona comprendida entre los 2 y $6^{\circ}$ de latitud $N$, localidades de Tumaco y Bahía Solano, y entre los 78 y $84^{\circ}$ de longitud $\mathrm{O}$ (Figura 1). Comprendió una malla de 25 estaciones biológicas que cubrieron las zonas costera y oceánica. Se consideraron como estaciones costeras, aquellas cuya distancia a la costa no excedía las $30 \mathrm{mn}$, distancia a la cual aún se espera influencia continental sobre las condiciones oceanográficas de la columna de agua (estaciones: 1, 3, 5, 7, 10, 12, 14 y 33); mientras que las estaciones cuya distancia a la costa fue mayor a $90 \mathrm{mn}$ se consideraron como oceánicas (estaciones: 75, 77, 79, 81, 107, 109, 111 y 113). Las estaciones de muestreo ubicadas entre las 30 y $90 \mathrm{mn}$ de la costa se clasificaron como de transición y no fueron consideradas para los análisis estadísticos longitudinales (costa-océano)

\section{MATERIALES Y MÉTODOS}

Se colectaron muestras de fitoplancton durante el crucero oceanográfico PACÍFICO XXXIX-ERFEN XXXVII, a bordo del buque oceanográfico de la Armada Nacional ARC Providencia, durante el 19 de septiembre y el 8 de octubre de 2004, siguiendo un plan de muestreo de 25 estaciones biológicas (Tabla I). En cada estación de muestreo se realizaron arrastres oblicuos de fitoplancton entre 0 y $200 \mathrm{~m}$ de profundidad utilizando una red cónica simple $(0.40 \mathrm{~m}$ diámetro), con ojo de malla de 60 micrómetros. El material colectado se fijó con formol al 10\% buferizado en agua de mar y se almacenó en frascos plásticos con capacidad de $500 \mathrm{ml}$. Las muestras se transportaron al laboratorio del Departamento de Biología de la Universidad del Valle, en donde después de ser homogeneizadas para resuspender el fitoplancton se les extrajo una submuetra de $3 \mathrm{ml}$ para realizar la identificación taxonómica siguiendo a Tomas $(1993,1997)$ y estimar la abundancia (Cel $\mathrm{m}^{-3}$ ) utilizando una cámara de conteo Sedgwick Rafter montada en un microscopio óptico invertido. Adicionalmente, se realizó un registro gráfico de las diferentes especies utilizando un sistema de captura de vídeo adosado a un microscopio óptico marca Olympus modelo $\mathrm{CH} 30$.

Para determinar la biomasa fitoplanctónica se colectaron muestras de agua de mar con botellas Niskin a profundidades estándar $(0,10,20,30,50$, $75,100$ y $150 \mathrm{~m})$. Se utilizó una bomba de vacío para filtrar $1000 \mathrm{ml}$ de agua a través de filtros de membrana (GF/F) con poro $0.47 \mu$ y diámetro de 47mm marca Whatman. Para evitar la acidificación del filtro, se adicionaron unas pocas gotas de carbonato de magnesio al finalizar el proceso de filtración. Cada filtro se colocó dentro de sobres de papel aluminio previamente rotulados y se almacenaron en un termo de nitrógeno líquido a $-170^{\circ} \mathrm{C}$ para evitar la degradación de los pigmentos y facilitar su posterior transporte al laboratorio. Se utilizó el método estándar de extracción con acetona al 90\% para cuantificar la concentración de clorofila$\alpha$, sustancia que es un indicador directo de la biomasa fitoplanctónica. Simultáneamente, en cada estación se registraron datos continuos de temperatura $\left({ }^{\circ} \mathrm{C}\right)$ y salinidad con un perfilador CTD, Seabird 19, con el propósito de establecer la descripción general de las condiciones oceanográficas en la zona de estudio.

Se realizó un proceso de interpolación y extrapolación con el propósito de lograr una representación espacial gráfica de las condiciones oceanográficas en el área de estudio. Considerando el reducido número de muestras (24 en toda el área de estudio), la ubicación espacial de las estaciones de muestreo (equiespaciadas) y la necesidad de describir las tendencias generales de las características oceanográficas (temperatura, salinidad, densidad) y biológicas (Clo- $\alpha$, abundancia, biomasa) evaluadas en el área de estudio, se utilizó el método de interpolación espacial Krigging, de la rutina Gridding del programa SURFER ${ }^{\circledR}$ 8.0. Este método genera mapas a partir de datos espaciados utilizando conjuntos de datos en tres dimensiones (XYZ), estableciendo un arreglo rectangular de los valores $\mathrm{Z}$ por medio de la interpolación y extrapolación de los valores suministrados, logrando de esta manera sugerir una tendencia espacial de la variable de interés a partir de los datos registrados.

Se utilizó el análisis no paramétrico de Mann-Whitney para evaluar la diferencia de abundancia y biomasa en una escala temporal diel (diurna-nocturna), y entre la zona costera y la zona oceánica. En este mismo sentido se utilizó 
el índice de diversidad de Shannon-Wiener ( $\left.\mathrm{H}^{\prime}\right)$ y heterogeneidad de los números de Hill $\left(\mathrm{N}_{1}\right.$ y $\left.\mathrm{N}_{2}\right)$, con el propósito de cuantificar atributos comunitarios relevantes como diversidad y riqueza de especies (Krebs, 1999)

El índice de Shannon-Wiener $\left(\mathrm{H}^{\prime}\right)$ es la medida de diversidad biológica más ampliamente utilizada en ecología. Proporciona una medida relativa de la diversidad de una muestra y varía según dos factores: la riqueza o número de especies contabilizadas y la equitabilidad o grado de proporción entre el número de individuos de cada especie en la muestra. Los números de Hill representan el número de especies presentes en la muestra que matemáticamente presentan una proporción tal, que pueden ser consideradas como especies abundantes (N1) o como especies muy abundantes (N2)

El índice de Shannon-Wiener se estimó como:

$$
\begin{aligned}
& H^{\prime}=\sum_{i=1}^{s}\left(p_{i}\right)\left(\log _{2} p_{i}\right) \\
& H^{\prime} \quad \text { donde, } \\
& \text { muestra el contenido de información de la } \\
& \text { (bits ind }{ }^{-1} \text { ) o medida de diversidad. } \\
& \text { pi es el número de especies. } \\
& \quad \begin{array}{l}
\text { es la proporción de toda la muestra que } \\
\text { pertenece al género } i .
\end{array}
\end{aligned}
$$

Mientras que los números de Hill $\left(\mathrm{N}_{1}\right.$ y $\left.\mathrm{N}_{2}\right)$ se estimaron como:

$$
\begin{aligned}
& N_{1}=e^{H^{\prime}} \\
& N_{2}=\frac{1}{D}=\frac{1}{\sum_{i=1}^{s} p_{i}^{2}}
\end{aligned}
$$

donde,

D es el índice de Simpson.

pi es la proporción de toda la muestra que pertenece al género $i$.
Todos los indicadores comunitarios fueron determinados mediante la rutina 'Species Diversity' del software de análisis ecológico 'Ecological Methodology' (Krebs, 2002)

\section{RESULTADOS}

Las condiciones oceanográficas en el área de estudio pueden clasificarse como 'normales' para el período de muestreo (Figura 2). La temperatura superficial del mar fue estable para toda la cuenca, con un rango de variación de $2.04^{\circ} \mathrm{C}$ (mínimo: $26.14^{\circ} \mathrm{C}$; máximo: $28.18^{\circ} \mathrm{C}$ ), siendo ligeramente mayor en la parte norte de la cuenca y en la zona costera (Figura 2A). La salinidad presentó una alta variabilidad superficial en la zona de estudio, con un rango de variación de 9.79 (mínimo: 24.78; máximo: 34.57). Se presentó un núcleo de máxima salinidad superficial en la estación oceanográfica 36 , ubicada en la parte centro-oriental de la cuenca (Figura 2B). Los niveles de oxígeno disuelto en la superficie presentaron un estrecho rango de variabilidad de $0.51 \mathrm{mLL}^{-1}$, con valores mínimo y máximo de 4.46 y $4.97 \mathrm{mLL}^{-1}$, respectivamente. Los sitios de máximo nivel de oxígeno superficial se encontraron en la parte transicional costa-océano en el Norte de la cuenca y hacia la parte sur-central de la cuenca (Figura 2C). Se registró una alta variación espacial de la densidad superficial en la zona de estudio, con un rango de $7.00 \mathrm{Kgm}^{-3}$ (mínimo: $14.67 \mathrm{kgm}^{-3}$; máximo: $21.67 \mathrm{kgm}^{-}$ ${ }^{3}$ ), siendo mayor la densidad superficial registrada después de la longitud de $82^{\circ} \mathrm{W}$ (Figura 2D)

Al establecer promedios entre 0 y $200 \mathrm{~m}$ para los parámetros físico-químicos no se detectó una diferencia significativa costa-océano entre los registros de temperatura (Mann-Whitney test, $p=0.09$ ); pero sí se estableció una diferencia significativa para la salinidad (Mann-Withney test, $\mathrm{p}=0.001$ ), el oxígeno disuelto (Mann Whitney test, $p=0.03$ ) y la densidad (Mann-Withney test, $p=0.010$ ), siendo la columna de agua en la zona costera de menor salinidad, menor concentración de oxígeno disuelto y menor densidad que en la zona oceánica (Figura 3)

Se identificaron un total de 126 morfoespecies de fitoplancton, pertenecientes a 37 géneros, siendo agrupados en tres clases principales: diatomeas (67.37\%), dinoflagelados (32.58\%) y silicoflagelados del género Dictyocha (0.05\%). Entre las diatomeas se destacó por su abundancia (Cel $\mathrm{m}^{-3}$ ) la especie 
Planktoniella sol; así como los géneros: Chaetoceros, Coscinodiscus, Thalassionema, Bacteriastrum, Rhizosolenia, Ditylum, Skeletonema, Nitzschia y Pseudonitzschia (Figura 4A y Figura 5). Estos dos últimos géneros se agruparon en un solo ítem debido a la dificultad para evaluar los caracteres diagnósticos (Tabla II). Se registraron florecimientos intensos de Planktoniella sol alcanzando abundancias del orden de 241 células en el conteo total de $3 \mathrm{ml}$, llegando incluso a representar el $74.38 \%$ de los individuos registrados en una estación. Los dinoflagelados más representativos pertenecieron a los géneros: Ceratium, Ornithocercus, Pyrophacus, Protoperidinium, Dinophysis, Ceratocorys, Gonyaulax, Podolampas y Amphisolenia (Figura 4B y Figura 6), mientras que los silicoflagelados sólo estuvieron representados por las especies Dictyocha fibula y $D$. polyactis (Figura 7), registrados en dos estaciones costeras (Tabla III)

De acuerdo con el índice de Shannon, la diversidad promedio de géneros de fitoplancton en la zona de estudio fue de 3.80 bits genero- ${ }^{-1}$, registrándose, según los números de Hill $\left(\mathrm{N}_{1}\right.$ y $\mathrm{N}_{2}$ ), catorce géneros abundantes y nueve géneros muy abundantes (Tabla IV). Entre las estaciones consideradas como costeras, la mayor diversidad se registró en la Estación 3 (3.55 bits género ${ }^{-1}$ ) con la presencia de doce géneros abundantes $\left(\mathrm{N}_{1}\right)$ y ocho géneros muy abundantes $\left(\mathrm{N}_{2}\right)$; mientras que en la zona oceánica la estación con mayor diversidad fue la 107 (2.77 bits género-1) con la presencia de cuatro géneros abundantes $\left(\mathrm{N}_{1}\right)$ y dos muy abundantes $\left(\mathrm{N}_{2}\right)$ (Tabla IV)

Según la representación gráfica de los valores del índice de Shannon y los números de Hill, la zona costera presentó mayor diversidad y número de especies abundantes y muy abundantes comparadas con la zona oceánica (Figura 8). No se registraron diferencias significativas para los indicadores de diversidad comunitaria entre el día y la noche, pero sí se detectaron diferencias significativas entre la zona costera y la zona oceánica (Tabla $\mathrm{V}$ ), siendo mayor la diversidad costera (Figura 8 y Figura 9)

La distribución espacial de la concentración de clorofila- $\alpha$, como indicador de biomasa fitoplanctónica, en el área de estudio estuvo entre $11.37 \mathrm{mg}$ Clo- $\alpha \mathrm{m}^{-2}$ (Estación 5) y $38.05 \mathrm{mg}$ Clo- $\alpha \mathrm{m}^{-2}$ (estación 75) (Tabla VI). No se detectaron diferencias significativas para la concentración de Clo- $\alpha$ en el área de estudio (Mann-Whitney Test: Día - Noche,
$U=55, Z=1.11, p$-valor $=0.2852 ;$ Costa - Océano, $U=26, Z=0.63$, p-valor $=0.5737$ ). Sin embargo, se detectaron dos núcleos de alta concentración de clorofila- $\alpha$ en el área de estudio; el primero en el sector norte oceánico (Estación 75) y el otro en el sector norte costero (Estación 12). Un tercer núcleo de alta concentración de clorofila, pero más pequeño que los anteriores, se localizó en la Estación 49, en la parte sur costera de la cuenca (Figura 10)

\section{DISCUSIÓN}

Las condiciones de la CPC son particulares debido a que está sometida a variaciones estacionales de temperatura y salinidad causadas por la migración de la ZCIT, a lo largo del año, y los vientos alisios del norte y del sur; los cuales se desplazan desde los trópicos hacia el Ecuador geográfico, arrastrando consigo un alto porcentaje del agua evaporada de la superficie del mar (Forsberg, 1969). No obstante, uno de los factores que más influye en la distribución del plancton es la temperatura, la cual caracteriza las diferentes masas de agua, provocando que la distribución espacial de los organismos planctónicos sea altamente variable, ya que las características fisiológicas de estos organismos generalmente limitan las condiciones ambientales en las cuales pueden sobrevivir (Parsons et al., 1984)

Es importante destacar que el número de 37 géneros de organismos fitoplanctónicos encontrados corresponde a los capturados por medio del método convencional de muestreo de fitoplancton que excluye casi por completo las fracciones de tamaño menor al ojo de red (60 micras en este caso). Como consecuencia de esto, no son incluidos los autótrofos conocidos por su tamaño como picoplancton ( 2 a 20 micras). El picoplancton incluye grupos como cocolitofóridos, crisomonádidos y euglénidos, y ha cobrado especial importancia ecológica en los últimos tiempos debido al importante papel que juega en la producción primaria y en el reciclaje de la materia orgánica que no pasa a niveles tróficos superiores, sino que se queda a nivel microscópico, lo que actualmente se conoce como 'loop' o bucle microbiano.

La composición de la comunidad fitoplanctónica en la CPC estuvo dominada por diatomeas, tanto en la zona costera como oceánica. Éstas integran un grupo extenso, que además de su gran número de especies se caracteriza por ser 
mayoritario en las zonas costeras. En el Pacífico colombiano abundan en las regiones centrales de los estuarios y en las desembocaduras de los ríos, además parece que su distribución espacial está estrechamente relacionada con los gradientes halinos locales (e.g. Dawes, 1991; Tomas, 1997)

El 'bloom' de Planktoniella sol detectado en las estaciones 75, 77, 79 y 107 delimita un área triangular que probablemente presentó condiciones adecuadas para la proliferación de esta especie. Esta especie se reporta como oceánica y se encuentra ampliamente distribuida en los mares tropicales y subtropicales del mundo (Jiménez, 1983), además de ser considerada como especie asociada a masas de aguas cálidas (Tomas, 1997)

La presencia de Dictyocha fibula (estaciones 33 y 14) y D. octonaria (Estación 14) en la zona costera concuerda con los reportes de estas especies en el golfo de Guayaquil, donde se describe a $D$. fibula como una especie cosmopolita y presente principalmente en aguas cálidas (Jiménez, 1983; Jiménez y Pasantes, 1978). Para la presente investigación se consideró este género como parte del grupo de los silicoflagelados, ya que son fitoflagelados unicelulares exclusivamente marinos con esqueleto tubular silíceo y un flagelo (Jiménez, 1983). La dualidad en la clasificación de este grupo como zooflagelados o fitoflagelados ha provocado muchas revisiones de clasificación. En este trabajo se sigue la propuesta taxonómica de Throndsen (Tomas, 1997) que agrupa a estos organismos en la división Chromophyta, clase Dictyochophyceae, orden Silicoflagellida; separándolos claramente de los Chrysomonadida que son considerados zooflagelados debido a su ausencia de cromatóforos (Tomas, 1997)

La provincia oceánica es mucho más extensa que la provincia nerítica (costera); sin embargo, la región costera tiende a ser mucho más viable en cuanto a la oferta de recursos, especialmente elementos nutritivos fundamentales, provenientes de la zona continental a través de la escorrentía para el fitoplancton (Miller, 2004). Por tanto, es de esperar una mayor diversidad de fitoplancton en esta región. Los resultados de esta investigación sugieren que la alta variabilidad en las condiciones físico-químicas y ambientales en la zona costera, debido a la influencia continental (escorrentía), estaría modulando la riqueza, diversidad y composición de la comunidad fitoplanctónica en la zona de estudio.

Aunque las condiciones oceanográficas durante la campaña de muestreo de esta investigación fueron consideradas como normales para la CPC (Giraldo et al., 2005), evaluar la distribución y abundancia del fitoplancton puede ser una herramienta valiosa para detectar la presencia de alteraciones en las condiciones oceanográficas de una zona específica. Por ejemplo, Vizcaíno (1993) y Salazar (2001) utilizaron los dinoflagelados como indicadores de condiciones El Niño para la CPC. Sin embargo, la relación entre variabilidad térmica ( $\mathrm{El}$ Niño) y grupo taxonómico (dinoflagelados) tiende a ser especie-específica, tal como lo sugieren Castillo y Vizcaino (1992) y Herrera y Giraldo (2006). En este sentido, los resultados obtenidos en esta investigación en relación con la composición, estructura, y variabilidad espacial de la comunidad fitoplanctónica en la CPC son consistentes con lo reportado por Sánchez (1996) y Medina (1997) para condiciones oceanográficas normales.

La variabilidad ambiental en la capa superior de la columna de agua del océano es el resultado del accionar conjunto de diferentes procesos oceanográficos que abarcan la microescala espaciotemporal (e.g. procesos turbulentos moleculares) hasta la escala oceánica (e.g. corrientes de viento, frentes, El Niño). Todos estos procesos afectan directamente la abundancia y estructura de los organismos planctónicos, incluyendo el fitoplancton, en la capa fótica (Murray et al., 1994). Por lo tanto, la información que se presenta en esta investigación se convierte en un insumo básico fundamental para comprender, desde un punto de vista holístico, el funcionamiento del sistema pelágico en la CPC al describir y cuantificar la variabilidad comunitaria y aporte en biomasa de la base de la trama trófica, como lo es el fitoplancton.

\section{AGRADECIMIENTOS}

A la Armada Nacional de Colombia, la Dirección General Marítima, DIMAR, y el Centro Control de Contaminación del Pacífico, CCCP, por la invitación extendida a la Universidad del Valle para participar de la campaña oceanográfica PACíFICO XXXIX-ERFEN XXXVII.

A la Sección de Biología Marina de la Universidad del Valle, en especial al Profesor Fernando Zapata, por facilitar el espacio físico y equipo óptico y digital requerido para el adecuado procesamiento de las muestras biológicas. 
Al Capitán Fragata Julián Augusto Reyna Moreno, al Capitán de Corbeta Javier Roberto Ortiz Galvis y a los suboficiales navales Émerson Esneider Espitia Espitia, Óscar Javier Fajardo Ospina y Juan Gabriel Rueda Bayona, por su colaboración y orientación para el procesamiento general de los datos oceanográficos durante la permanencia de D. Ramírez en el CCCP.

Al Comandante del buque oceanográfico ARC Providencia, Capitán Fragata Mario Moreno y a toda la tripulación, por el apoyo logístico durante la fase de campo.

Al Biólogo Jorge Tovar, adscrito al Laboratorio de Biología del CCCP-Tumaco, por la orientación inicial para el análisis e identificación de las muestras biológicas.

\section{LITERATURA CITADA}

Andrade, C. 1992. Movimiento geostrófico en el Pacífico colombiano. Boletín Científico ClOH, (12): 23-38.

Barnes, R. y R. Hughes. 1999. An introduction to Marine Ecology. Tercera edición. Oxford, Blackwell Science. 286 pp.

Castillo, F, y Z. Vizcaino. 1992. Los indicadores biológicos del fitoplancton y su relación con el FEN 1991-1992 en el Pacífico colombiano. Boletín Científico $\mathrm{CIOH}$ (12):13-22.

Dawes, C. 1991. Botánica Marina. México Editorial Limusa. 673 pp.

Forsberg, E. 1969. Estudio sobre la climatología, Oceanografía y pequerías del Panamá Bight. Bulletin of the Interamerican Tropical Tuna Comisión (14): 49-365.

Giraldo, A., D. Ramírez y M. Murcia. 2005. Producción primaria, biomasa fitoplanctónica y composición taxonómica del fitoplancton y zooplancton del Pacífico colombiano: una aproximación holística a la base del sistema pelágico. Universidad del Valle. Facultad de Ciencias. Cali. Colombia. 29 pp.

Herrera, L. y A. Giraldo. 2006. Estructura comunitaria de los dinoflagelados en la bahía de Buenaventura (Pacífico colombiano): relación con la temperatura superficial del mar. Revista Investigaciones Marinas, Valparaíso. (en prensa).
Jiménez, R. 1983. Acta oceanográfica del Pacífico. Diatomeas y silicoflagelados del fitoplancton del golfo de Guayaquil. Segunda edición. INOCAR, Ecuador. 280 pp.

Jiménez R. y F. Pesantes. 1978. Fitoplancton, producción primaria y pigmentos en aguas costeras ecuatorianas. Guayaquil, Instituto Oceanográfico de la Armada. 30 pp.

Johnson, W. y D. Allen. 2005. Zooplankton of the Atlantic and Gulf coast: a guide to their identification and ecology. The Johns Hopkins University Press. Blatimore, USA. 379 pp.

Krebs, C. 1999. Ecological Methodology. 2nd Ed. Benjamin-Cummings.

Krebs, C, 2002. Programs for Ecological methodology, 2nd Ed. Software. University of British Columbia. Canada. http://www.zoology. ubc.ca/ krebs.

Lalli, C. y T. Parsons. 1997. Biological oceanography: an introduction. 2nd Ed. Butterworth and Heinemann. Oxford, England. 314 pp.

Mann, K. 2000. Ecology of coastal waters with implications for management, 2nd ed. Boston, Blackwell Science. 406 pp.

Mann, K. y J. Lazier. 1996. Dynamics of marine ecosystems: biological-physical interactions in the oceans, 2nd ed. Boston, Blackwell Science.

Medina, L. 1997. Composición y comportamiento del fitoplancton en el área del Pacifico colombiano, años 1995-1997. Boletín Científico CCCP, (6): 95-108.

Miller, C. 2004. Biological Oceanography. Editorial Blackwell Publishing Company. Malden, USA. 402 pp.

Murray, J., R. Barber, M. Roman, M. Bacon y R. Feely. 1994. Physical and biological controls on carbon cycling in the equatorial Pacific. Science 266, 58-65 pp.

Nybaken, J. 1997. Marine Biology: an ecological approach. cuarta edición. New York, USA. Editorial Addisson Wesley. 481 pp. 
Parsons, R., M. Takahashi y B. Musgrave. 1984. Biological Oceanographic processes. 3a ed. Pergamon Press, Great Britain. 330 pp.

Prahl, H., J. Cantera y R. Contreras. 1990. Manglares y hombres del Pacífico colombiano. Ed. Presencia, Cali, Colombia.184 pp.

Rodríguez-Rubio, E., W. Schneider y R. Abarca del Río. 2003. On the seasonal circulation within Panama Bight derived from satellite observations of winds, altimetry and sea surface temperature. Geophy. Res. Lett. 30(7): 1410-1413.

Salazar, C. 2001. Caracterización de la estructura fitoplanctónica en aguas del Pacífico colombiano y su relación con eventos asociados al fenómeno El Niño. Cali, 59 pp. Tesis de Pregrado Biología con Mención (Biología Marina). Universidad del Valle. Facultad de Ciencias.
Sánchez, E. 1996. Caracterización espacial del fitoplancton nerítico en el Pacífico colombiano durante julio-agosto de 1994. Cali, 61 pp. Tesis de grado con Mención (Biología Marina). Universidad del Valle.

Tomas, C. 1993. Marine phytoplankton: a guide to naked flagellates and coccolithophorids. Academica Press, INC, San Diego. 263 pp.

Tomas, C. 1997. Identifying marine phytoplancton. Academia Press. San Diego. 858 pp.

Vizcaíno, Z. 1993. Fitoplancton del Pacífico colombiano como indicador del fenómeno El Niño. Cali, 71 pp. Tesis de grado con Mención (Biología Marina). Universidad del Valle.

FIGURAS Y TABLAS

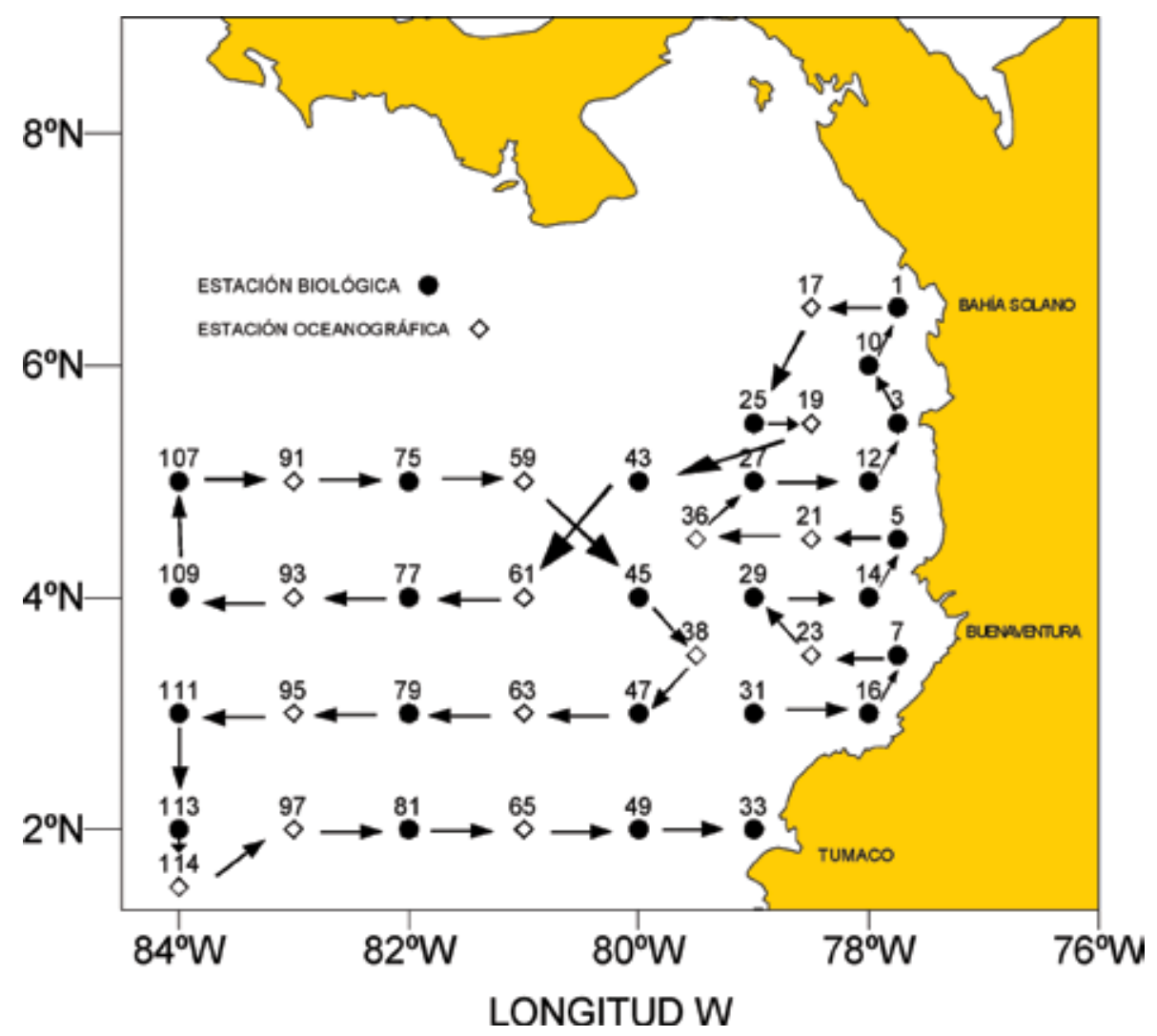

Figura 1. Ubicación de las estaciones de muestreo (físicas, químicas y biológicas) en la CPC durante el crucero oceanográfico PACíFICO XXXIX-ERFEN XXXVII, a bordo del ARC Providencia entre el 19 de septiembre y 8 de octubre de 2004 (Fuente: Plan operacional de crucero CCCP) 

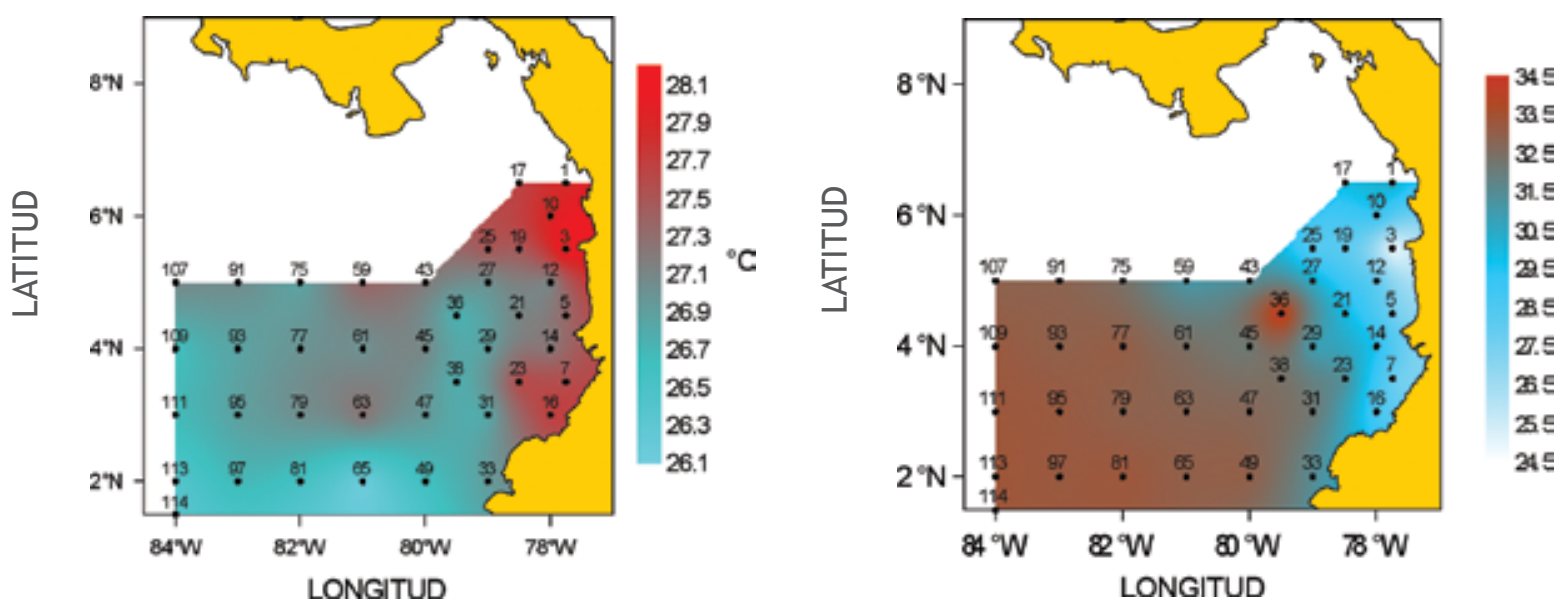

A

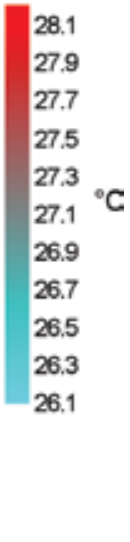

B
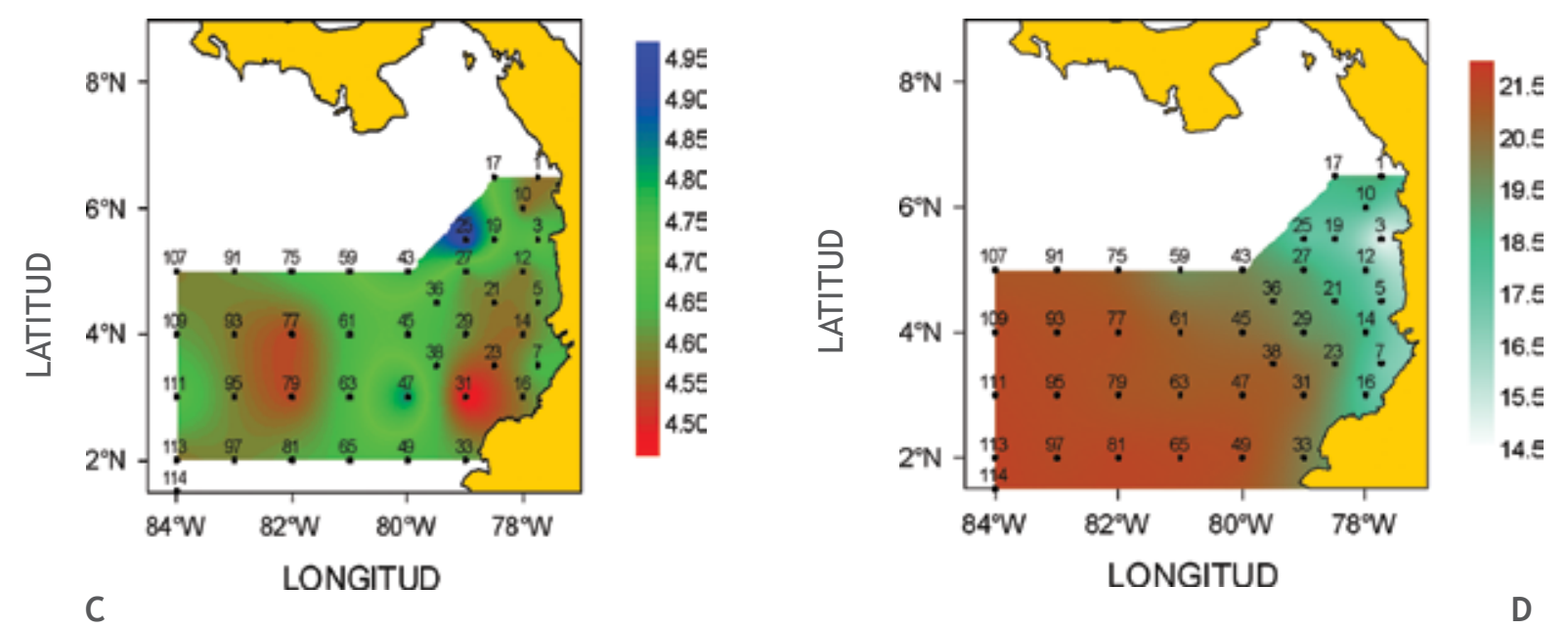

Figura 2. Variabilidad espacial de las condiciones oceanográficas de A) Temperatura $\left({ }^{\circ} \mathrm{C}\right)$, B) Salinidad, C) Oxígeno Disuelto Superficial $\left(\mathrm{mgml}^{-1}\right)$ y D) Densidad $\left(\sigma_{t}\right)$, en la CPC durante el crucero oceanográfico PACíFICO XXXIX-ERFEN XXXVII, a bordo del ARC Providencia entre el 19 de septiembre y el 8 de octubre 2004. 

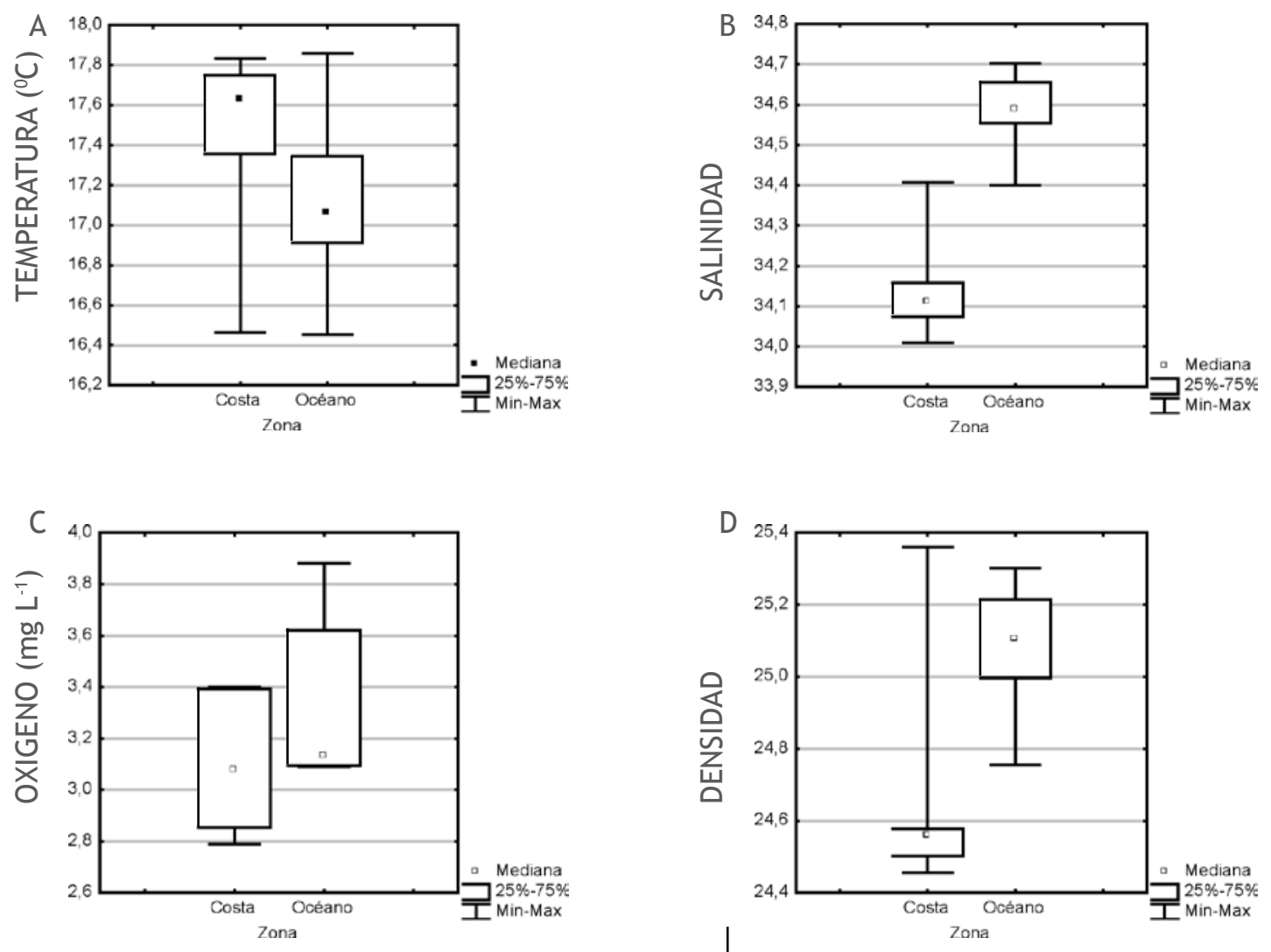

Figura 3. Comparación de las condiciones oceanográficas de A) Temperatura, B) Salinidad y C) Densidad, para valores promediados entre 0 y $200 \mathrm{~m}$ de la columna de agua, entre las zonas costera y oceánica de la CPC durante el crucero oceanográfico PACÍFICO XXXIX-ERFEN XXXVII, a bordo del ARC Providencia, entre el 19 de septiembre y 8 de octubre 2004. Estaciones costeras: 33, 7, 14, 5, 12, 3, 10 y 1; estaciones oceánicas: $75,107,109,77,79,111,113$ y 81.

\section{A. Diatomeas}

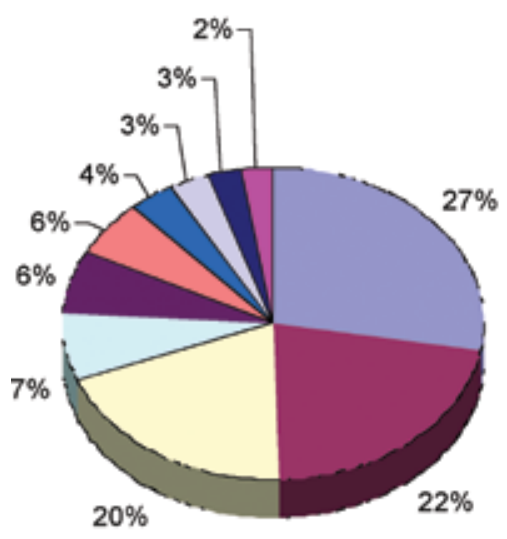

\section{B. Dinoflagelados}

口 Planktoniella sol
- Chaetoceros
$\square$ Coscinodiscus
$\square$ Thalassionema
- Otros
$\square$ Bacteriastrum
- Rhizosolenia
$\square$ Ditylum
- Nitzschia-
Pseudonitzschia
口 Skeletonema

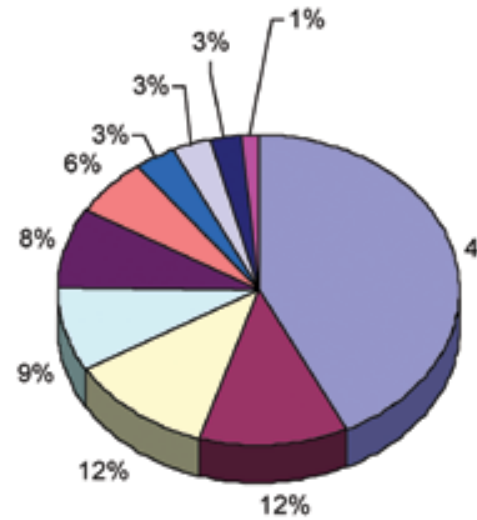

口 Ceratium

- Omithocercus

口Pyrophacus 口 Protoperidinium

- Dinophysis

a Ceratocorys

- Gonyaulax

口 Podolampas

- Amphisolenia

a Otros

Figura 4. Composición porcentual de la comunidad de diatomeas (A) y dinoflagelados (B) en la CPC durante el crucero oceanográfico PACÍFICO XXXIX-ERFEN XXXVII, a bordo del ARC Providencia, entre el 19 de septiembre y el 8 de octubre 2004. 


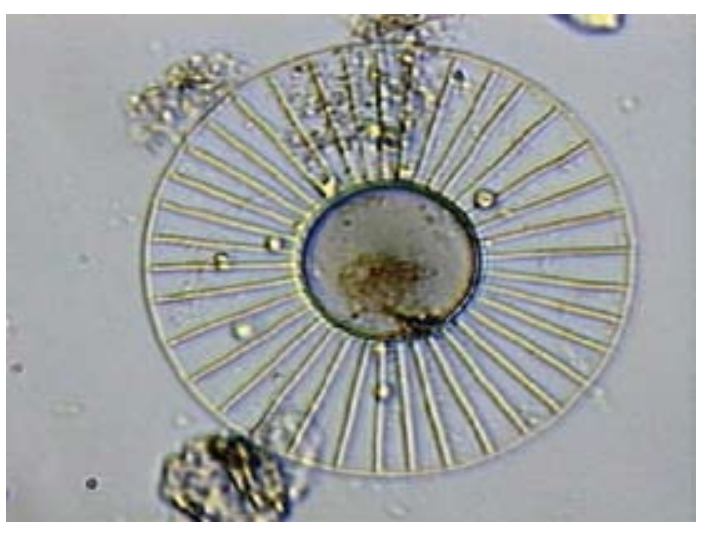

A

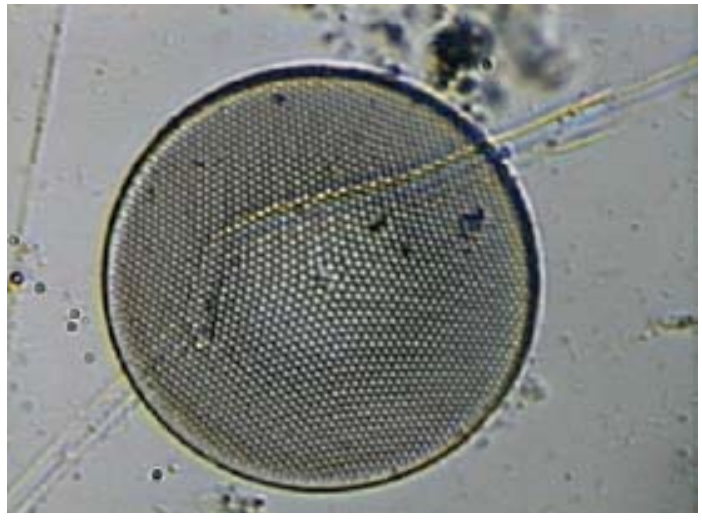

C

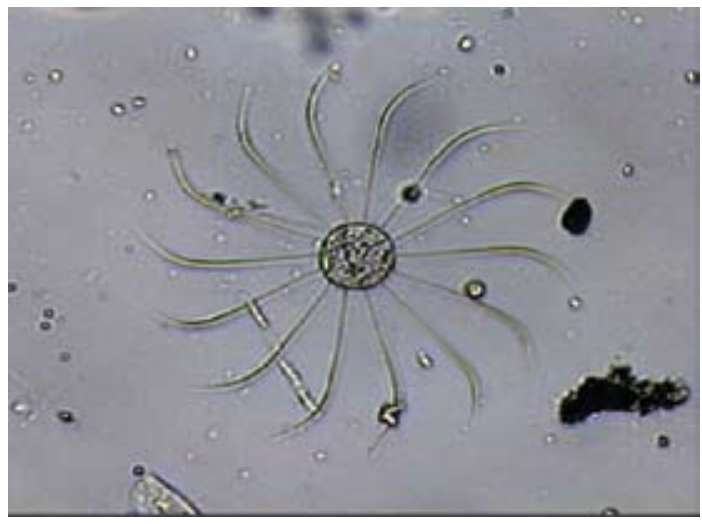

E

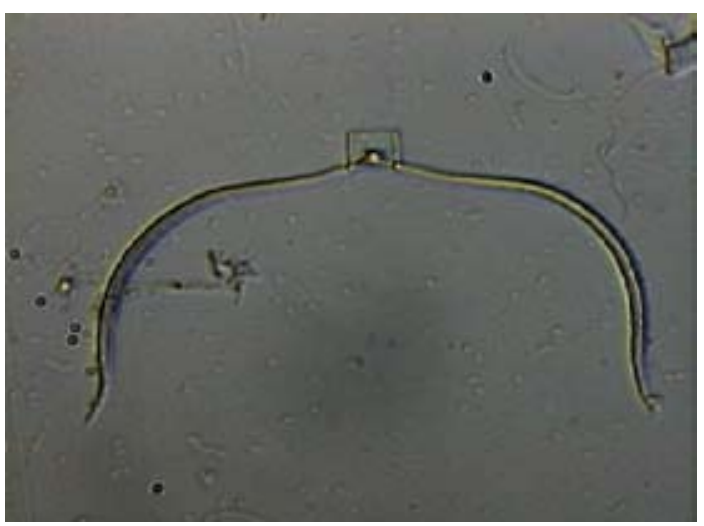

B

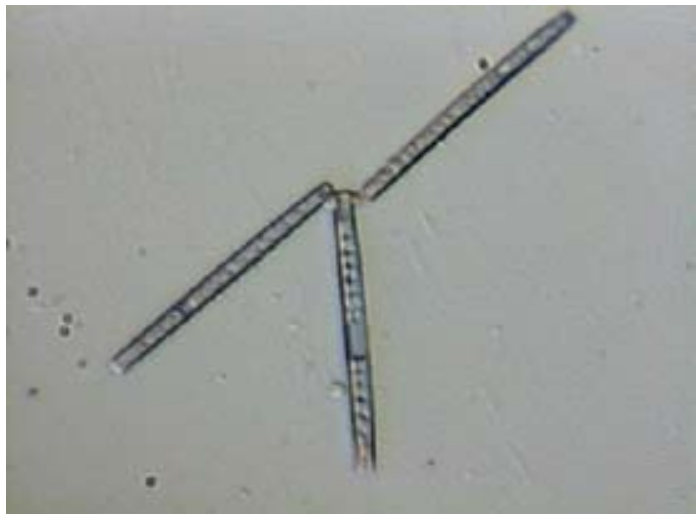

D

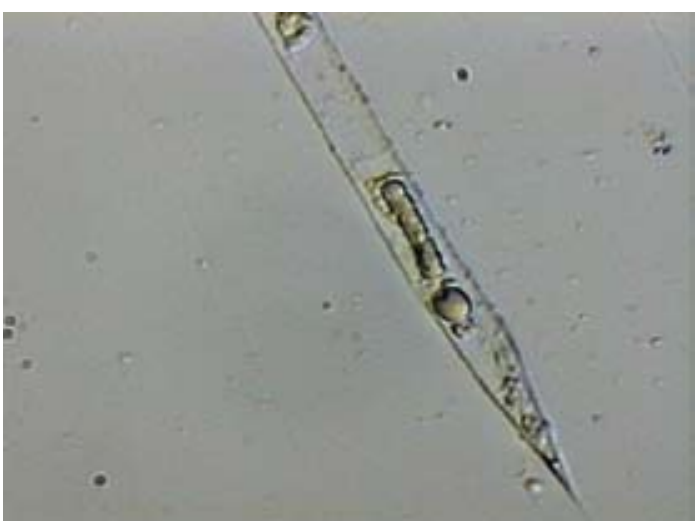

F 


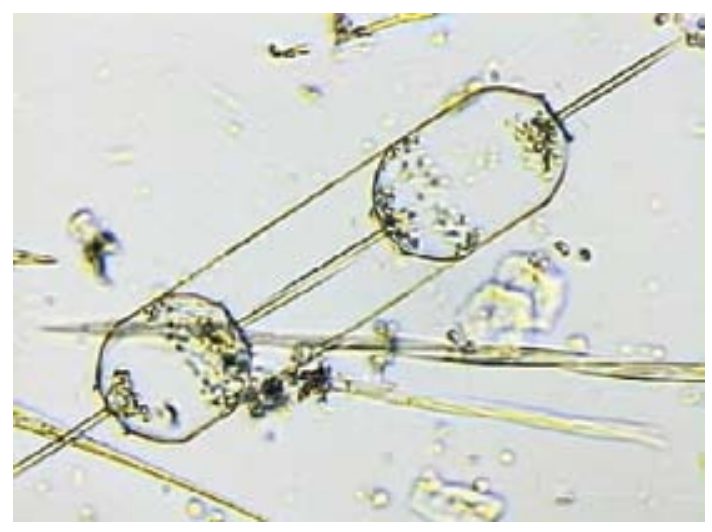

G

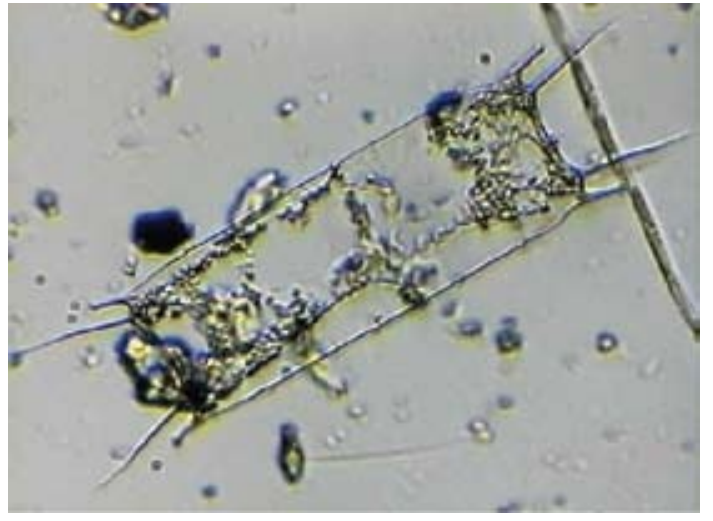

$\mathrm{H}$

Figura 5. Registro de los principales géneros de diatomeas halladas en la CPC durante el crucero oceanográfico PACíFICO XXXIX-ERFEN XXXVII, a bordo del ARC Providencia, entre el 19 septiembre y 8 de octubre de 2004. A: Planktoniella sp., B: Chaetoceros sp., C: Coscinodiscus sp., D: Thalassionema sp., E: Bacteriadium sp., F:Rhizosolenia sp., G: Ditylum sp., H: Odontella sp.

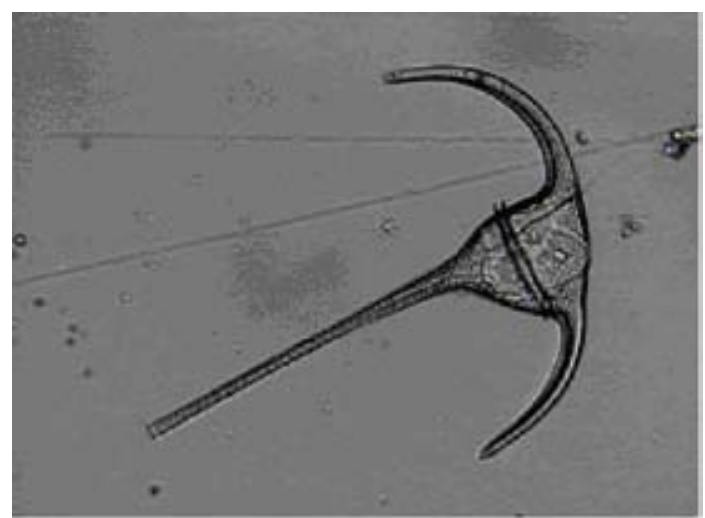

A

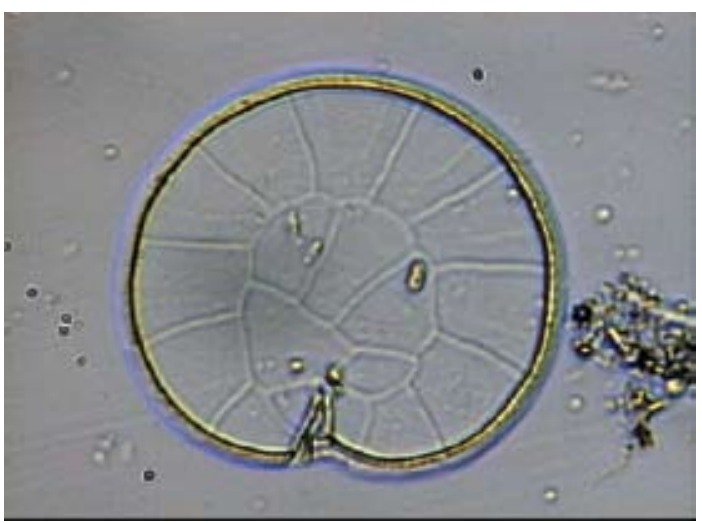

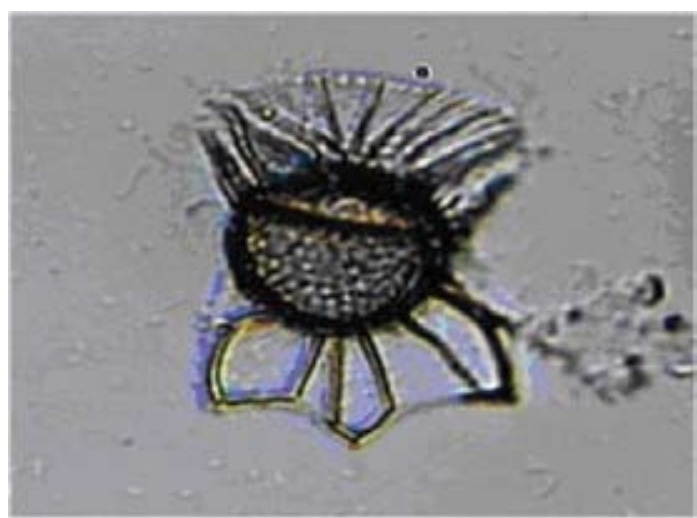

B

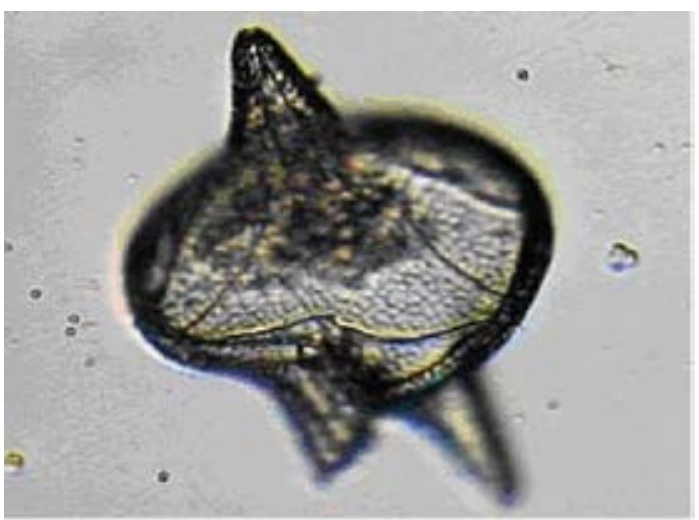




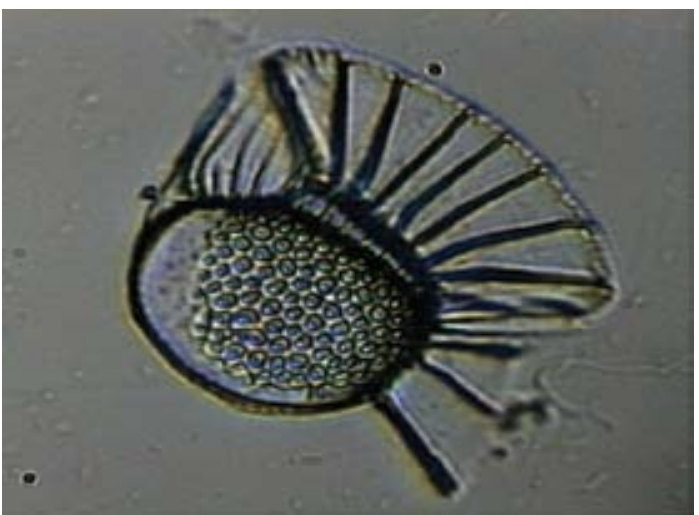

E

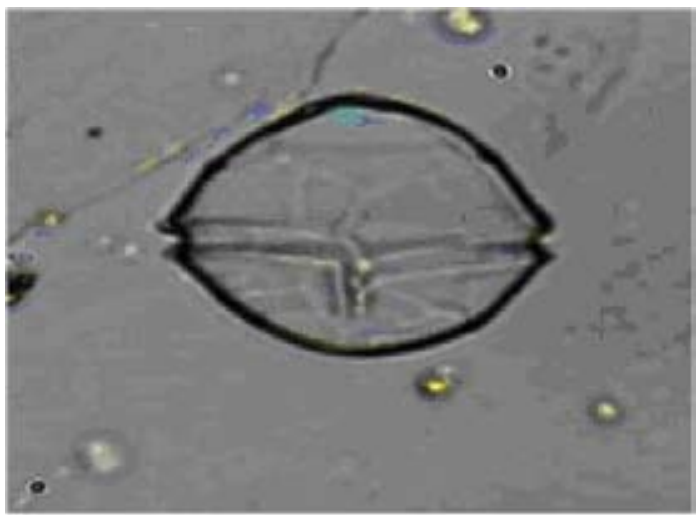

G

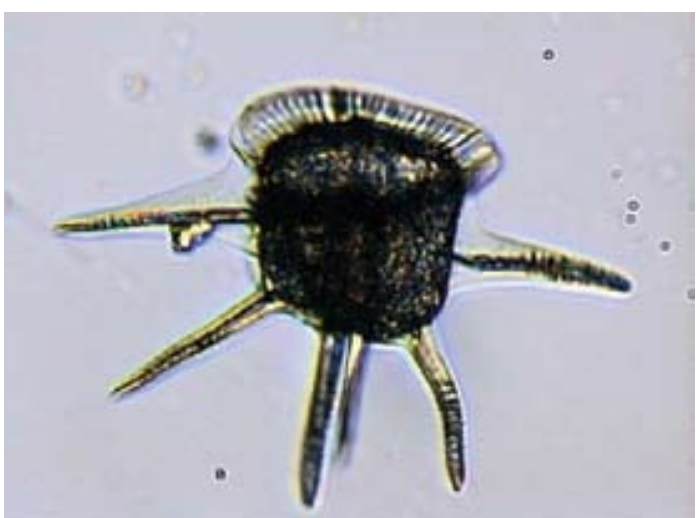

$\mathbf{F}$

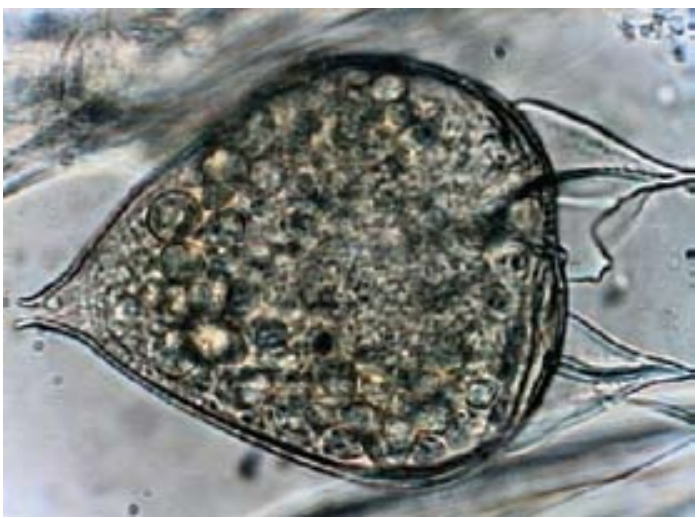

H

Figura 6. Registro de los principales géneros de dinoflagelados hallados en la CPC durante el crucero oceanográfico PACíFICO XXXIX-ERFEN XXXVII, a bordo del ARC Providencia, entre el 19 de septiembre y el 8 de octubre 2004. A: Ceratium sp., B: Orinithocercus sp., C: Pyrophaus sp., D: Protoperidinium sp., E: Dinophysis sp., F: Ceratocorys sp., G: Gonyaulax sp., H: Podolampas sp.

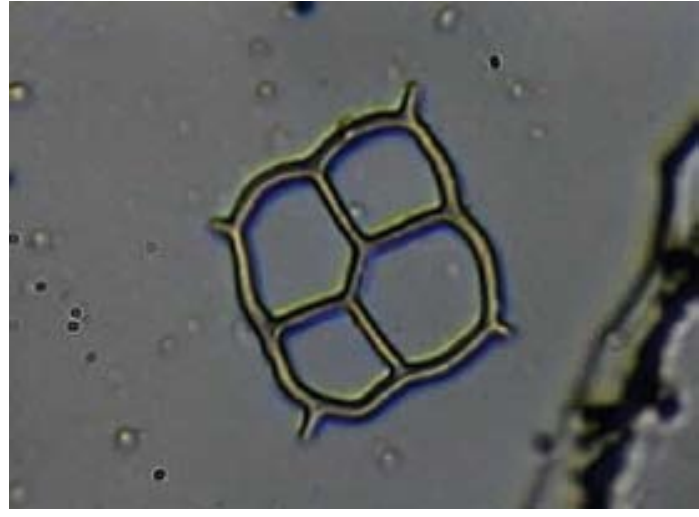

A

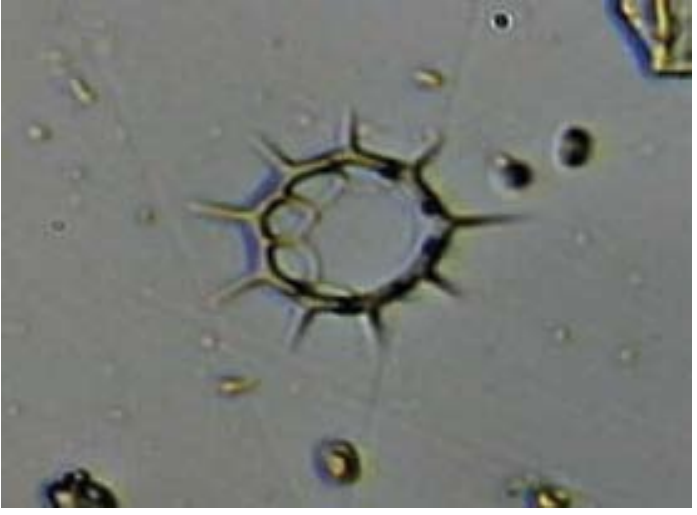

B

Figura 7. Registro fotográfico de los principales géneros de silocoflagelados registrados en la CPC durante el crucero oceanográfico PACÍFICO XXXIX-ERFEN XXXVII, a bordo del ARC Providencia entre el 19 de septiembre y el 8 de octubre 2004. A: Dyctiocha sp., B: Polyactic sp. 


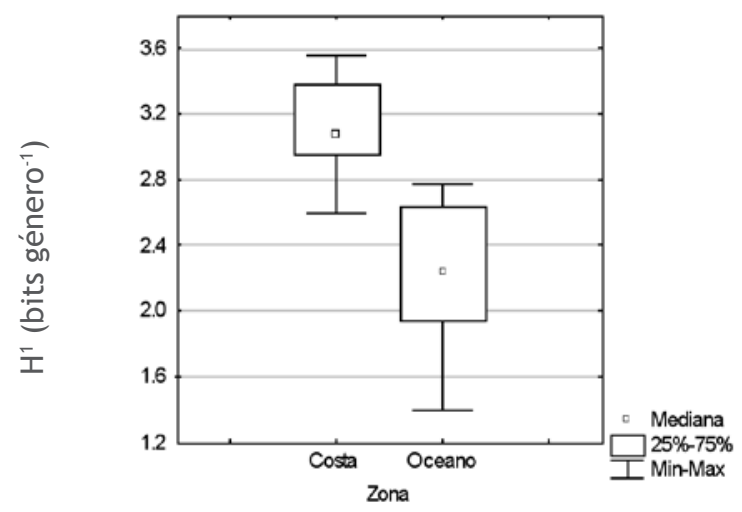

A

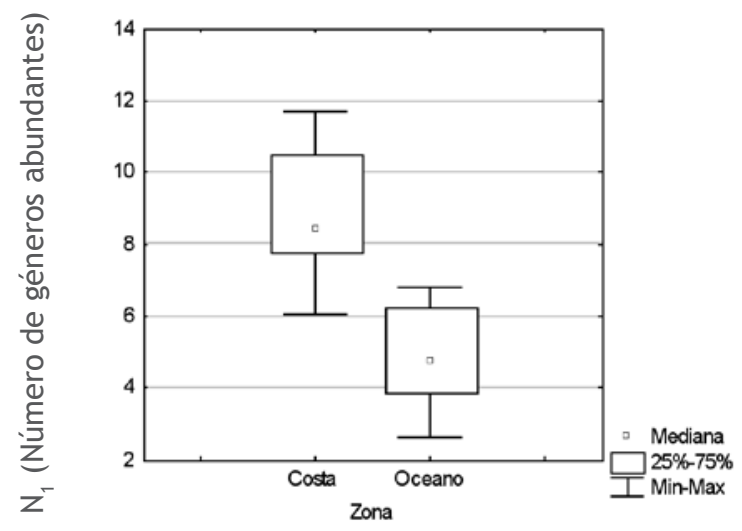

B

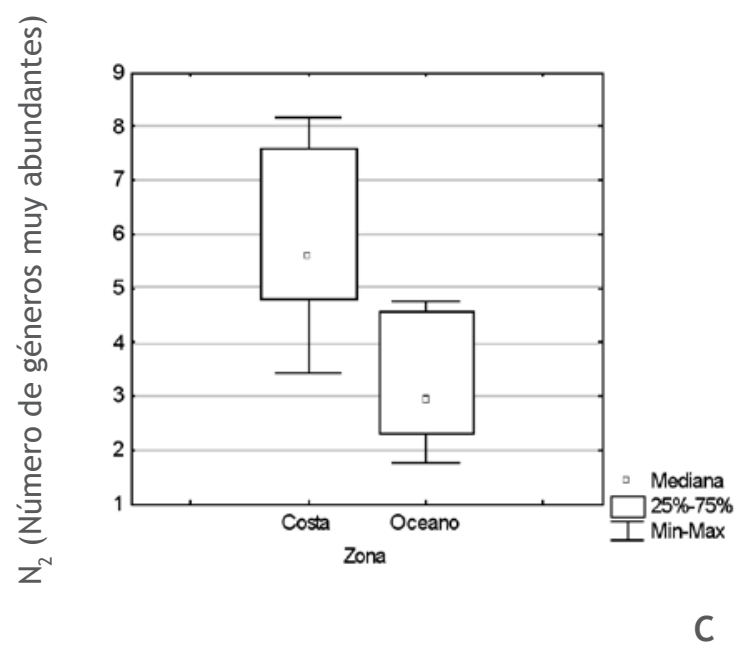

Figura 8. Comparación de los indicadores de diversidad comunitaria del fitoplancton entre la zona costera y zona oceánica de la CPC durante el crucero oceanográfico PACíFICO XXXIX-ERFEN XXXVII, a bordo del ARC Providencia entre el 19 de septiembre y el 8 de octubre de 2004. A) Shannon (H'); B) Segundo Número de Hill $\left(\mathrm{N}_{1}\right)$; C) Tercer Número de Hill $\left(\mathrm{N}_{2}\right)$ 

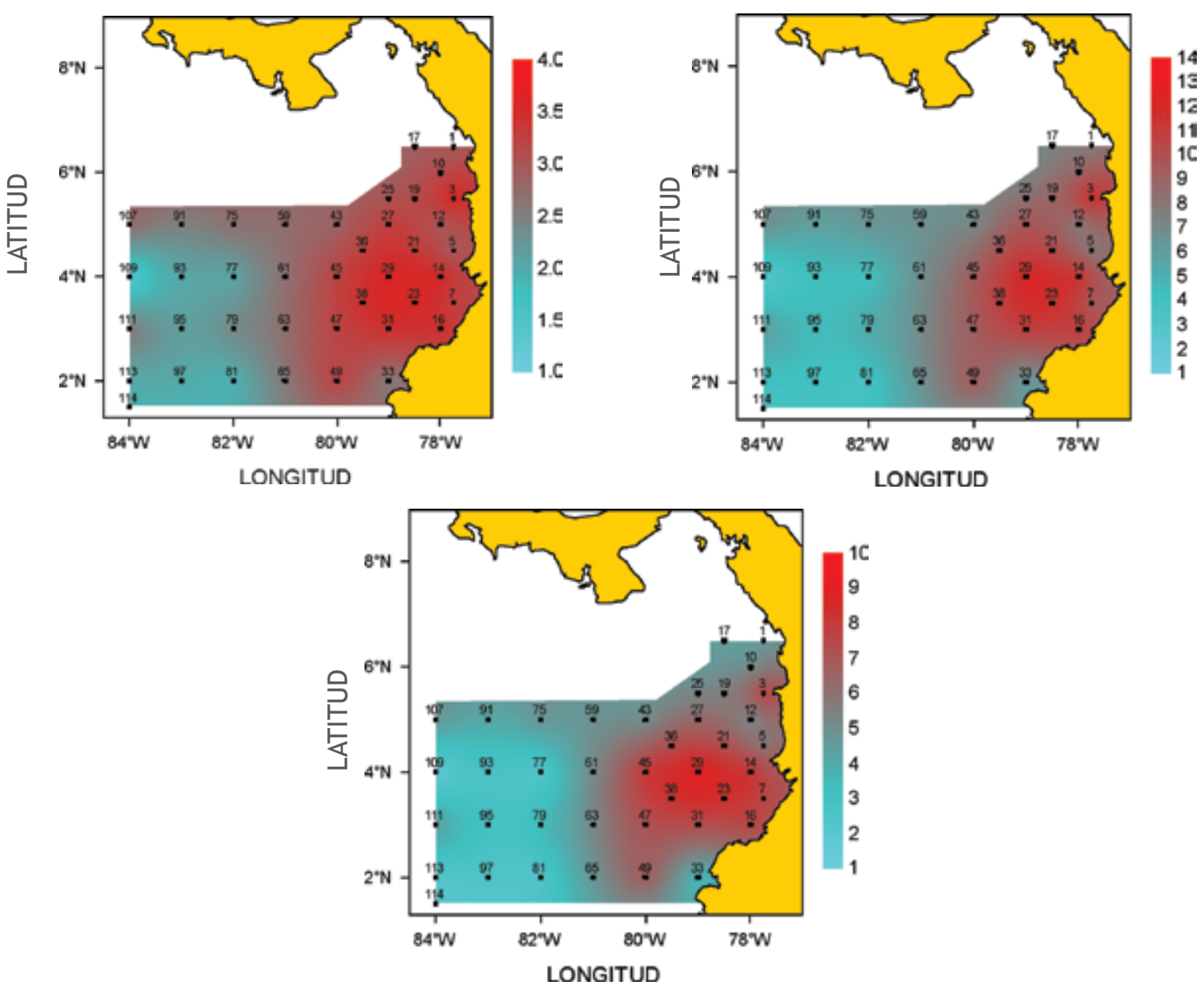

Figura 9. Distribución espacial de los indicadores de diversidad comunitaria del fitoplancton en la CPC durante el crucero oceanográfico PACÍFICO XXXIX-ERFEN XXXVII, a bordo del ARC Providencia entre el 19 de septiembre y el 8 de octubre 2004. A) Shannon (H') - Diversidad; B) Segundo Número de Hill $\left(\mathrm{N}_{1}\right)$ - Número de géneros abundantes; $\mathrm{C}$ ) Tercer Número de Hill $\left(\mathrm{N}_{2}\right)$ - Número de géneros muy abundantes.

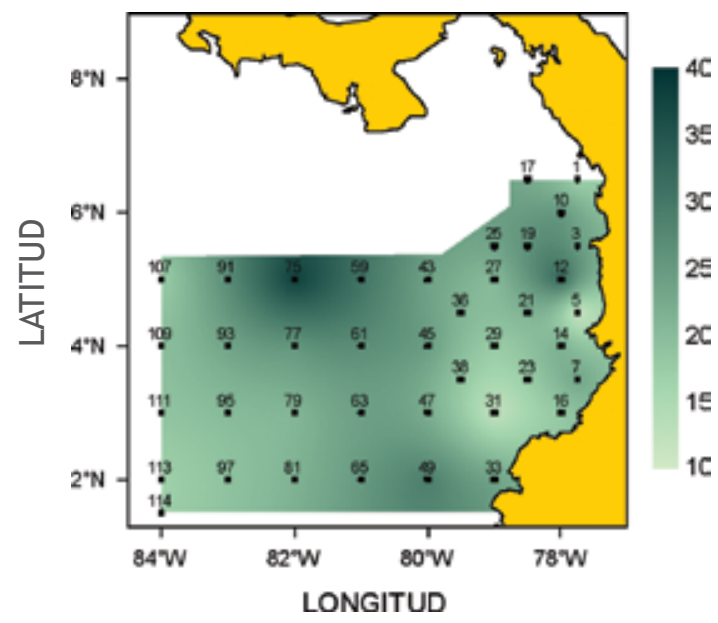

Figura 10. Distribución espacial de la concentración de Clorofila- $\alpha$ ( $\mathrm{mg} \mathrm{m}^{-2}$ : integrado en la capa de influencia friccional 0 - $50 \mathrm{~m}$ ) en la CPC durante el crucero oceanográfico PACÍFICO XXXIX-ERFEN XXXVII, a bordo del ARC Providencia entre el 19 de septiembre y el 8 de octubre de 2004. 
Tabla I. Localización de las estaciones biológicas de muestreo en la CPC durante el crucero oceanográfico PACÍFICO XXXIX-ERFEN XXXVII, a bordo del ARC Providencia entre el 19 de septiembre y el 8 de octubre 2004. NA: No considerada por baja profundidad.

\begin{tabular}{|c|c|c|c|c|c|c|}
\hline Estación & $\begin{array}{l}\text { Fecha } \\
\text { (d/m/a) }\end{array}$ & Hora & $\begin{array}{l}\text { Latitud } \\
\text { (N) }\end{array}$ & $\begin{array}{l}\text { Longitud } \\
\text { (W) }\end{array}$ & $\begin{array}{l}\text { Profundidad } \\
(\mathrm{m})\end{array}$ & Carácter \\
\hline 1 & $23 / 09 / 2004$ & $04: 48$ & $6^{\circ} 30^{\prime} 00^{\prime \prime}$ & 77²5’00”' & 3200 & Costera \\
\hline 3 & $22 / 09 / 2004$ & $18: 15$ & $5^{\circ} 30^{\prime} 00^{\prime \prime}$ & 77²5’00”' & 1700 & Costera \\
\hline 5 & $21 / 09 / 2004$ & 07:00 & $4^{\circ} 30^{\prime} 00^{\prime \prime}$ & 77²5’00”' & 1225 & Costera \\
\hline 7 & $20 / 09 / 2004$ & $02: 20$ & $3^{\circ} 30^{\prime} 00^{\prime \prime}$ & 77²5’00”' & 300 & Costera \\
\hline 10 & $22 / 09 / 2004$ & $23: 35$ & $6^{\circ} 00^{\prime} 00^{\prime \prime}$ & $78^{\circ} 00^{\prime} 00^{\prime \prime}$ & 3000 & Costera \\
\hline 12 & $22 / 09 / 2004$ & 07:00 & $5^{\circ} 00^{\prime} 00^{\prime \prime}$ & $78^{\circ} 00^{\prime} 00^{\prime \prime}$ & 3600 & Costera \\
\hline 14 & $21 / 09 / 2004$ & $02: 30$ & $4^{\circ} 00^{\prime} 00^{\prime \prime}$ & $78^{\circ} 00^{\prime} 00^{\prime \prime}$ & 1260 & Costera \\
\hline 16 & 19/09/2004 & $23: 00$ & $3^{\circ} 00^{\prime} 00^{\prime \prime}$ & $78^{\circ} 00^{\prime} 00^{\prime \prime}$ & 70 & NA \\
\hline 25 & $25 / 09 / 2004$ & $03: 52$ & $6^{\circ} 00^{\prime} 00^{\prime \prime}$ & 7900’00” & 3120 & Transición \\
\hline 27 & $21 / 09 / 2004$ & $23: 45$ & 500’00” & 7900’00”' & 3000 & Transición \\
\hline 29 & $20 / 09 / 2004$ & $18: 45$ & $4^{\circ} 00^{\prime} 00^{\prime \prime}$ & 7900’00” & 3267 & Transición \\
\hline 31 & $19 / 09 / 2004$ & $14: 40$ & $3^{\circ} 00^{\prime} 00^{\prime \prime}$ & 7900’00” & 2700 & Transición \\
\hline 33 & $08 / 10 / 2004$ & $04: 30$ & $2^{\circ} 00^{\prime} 00^{\prime \prime}$ & 7900’00” & 1070 & Costera \\
\hline 43 & $25 / 09 / 2004$ & $18: 25$ & $5^{\circ} 00^{\prime} 00^{\prime \prime}$ & $80^{\circ} 00^{\prime} 00^{\prime \prime}$ & 3950 & Transición \\
\hline 45 & $28 / 09 / 2004$ & $19: 40$ & $4^{\circ} 00^{\prime} 00^{\prime \prime}$ & $80^{\circ} 00^{\prime} 00^{\prime \prime}$ & 1600 & Transición \\
\hline 47 & $04 / 10 / 2004$ & 05:15 & $3^{\circ} 00^{\prime} 00^{\prime \prime}$ & $80^{\circ} 00^{\prime} 00^{\prime \prime}$ & 2103 & Transición \\
\hline 49 & $07 / 10 / 2004$ & $16: 53$ & $2^{\circ} 00^{\prime} 00^{\prime \prime}$ & $80^{\circ} 00^{\prime} 00^{\prime \prime}$ & 2871 & Transición \\
\hline 75 & $28 / 09 / 2004$ & 05:10 & $5^{\circ} 00^{\prime} 00^{\prime \prime}$ & $82^{\circ} 00^{\prime} 00^{\prime \prime}$ & 879 & Oceánica \\
\hline 77 & $26 / 09 / 2004$ & $20: 45$ & $4^{\circ} 00^{\prime} 00^{\prime \prime}$ & $82^{\circ} 00^{\prime} 00^{\prime \prime}$ & 1205 & Oceánica \\
\hline 79 & $04 / 10 / 2004$ & $22: 00$ & $3^{\circ} 00^{\prime} 00^{\prime \prime}$ & $82^{\circ} 00^{\prime} 00^{\prime \prime}$ & 2657 & Oceánica \\
\hline 81 & $07 / 10 / 2004$ & 01:40 & $2^{\circ} 00^{\prime} 00^{\prime \prime}$ & $82^{\circ} 00^{\prime} 00^{\prime \prime}$ & 2533 & Oceánica \\
\hline 107 & $27 / 09 / 2004$ & $17: 20$ & $5^{\circ} 00^{\prime} 00^{\prime \prime}$ & $84^{\circ} 00^{\prime} 00^{\prime \prime}$ & 3000 & Oceánica \\
\hline 109 & $27 / 09 / 2004$ & $07: 15$ & $4^{\circ} 00^{\prime} 00^{\prime \prime}$ & $84^{\circ} 00^{\prime} 00^{\prime \prime}$ & 2324 & Oceánica \\
\hline 111 & $06 / 10 / 2004$ & $00: 30$ & $3^{\circ} 00^{\prime} 00^{\prime \prime}$ & $84^{\circ} 00^{\prime} 00^{\prime \prime}$ & 2300 & Oceánica \\
\hline 113 & $06 / 10 / 2004$ & $07: 25$ & $2^{\circ} 00^{\prime} 00^{\prime \prime}$ & 8400’00” & 3131 & Oceánica \\
\hline
\end{tabular}




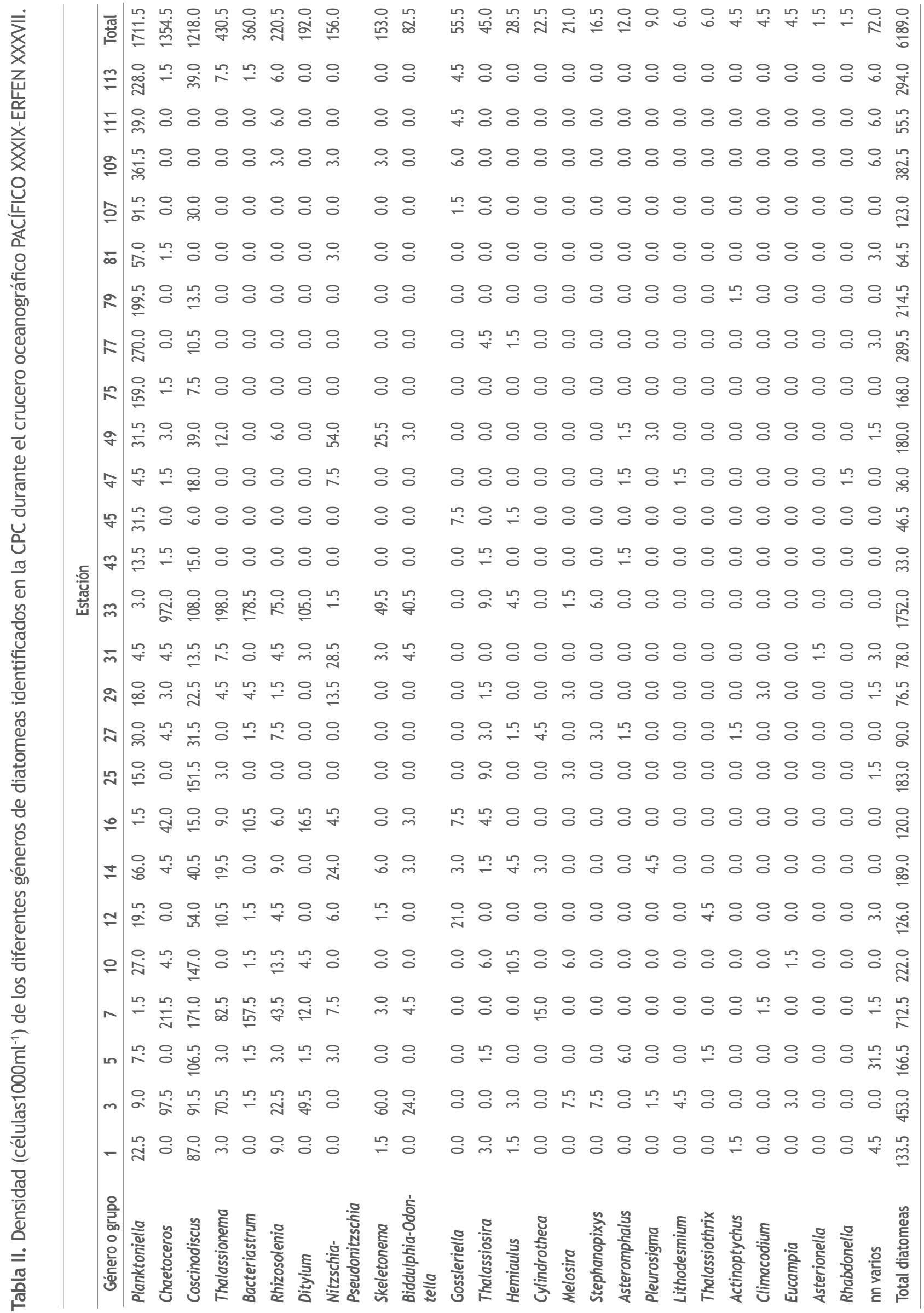




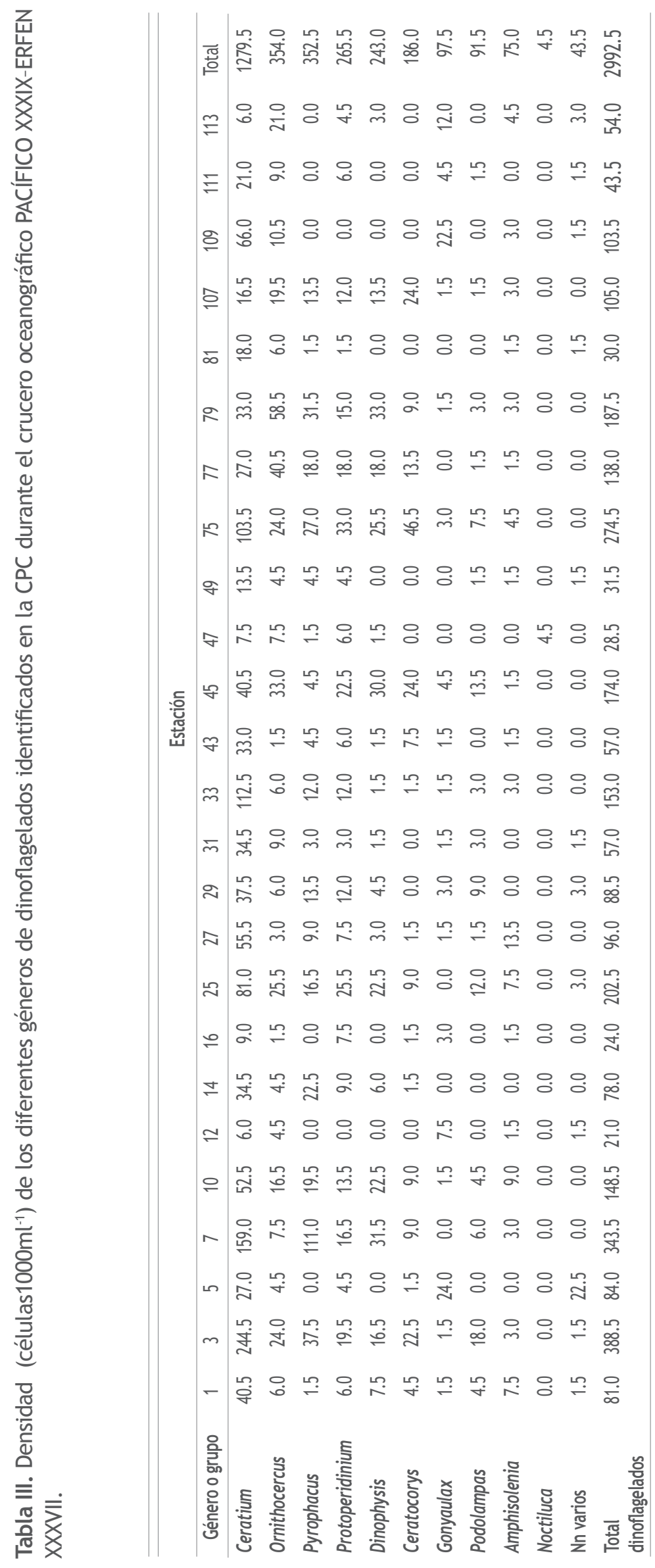


Tabla IV. Índice de diversidad (Shannon: H') y heterogeneidad (Números de Hill $\mathrm{N}_{1}$ y $\mathrm{N}_{2}$ ) de géneros de fitoplancton en la CPC durante el crucero oceanográfico PACÍFICO XXXIX-ERFEN XXXVII, a bordo del ARC Providencia entre el 19 de septiembre y el 8 de octubre de 2004

\begin{tabular}{cccccccc}
\hline \hline Estación & $\mathbf{H}^{\prime}$ & $\mathbf{N}_{1}$ & $\mathbf{N}_{2}$ & Estación & $\mathbf{H}^{\prime}$ & $\mathbf{N}_{1}$ & $\mathbf{N}_{2}$ \\
\hline 1 & 2.94 & 7.69 & 4.56 & 43 & 2.84 & 7.14 & 4.99 \\
3 & 3.55 & 11.71 & 7.58 & 45 & 3.22 & 9.30 & 8.07 \\
5 & 2.98 & 7.88 & 5.90 & 47 & 3.21 & 9.24 & 7.14 \\
7 & 3.26 & 9.57 & 7.59 & 49 & 3.22 & 9.31 & 6.83 \\
10 & 3.15 & 8.87 & 5.08 & 75 & 2.70 & 6.48 & 4.74 \\
12 & 3.01 & 8.02 & 5.32 & 77 & 2.06 & 4.18 & 2.39 \\
14 & 3.52 & 11.48 & 8.18 & 79 & 2.41 & 5.34 & 3.45 \\
16 & 3.45 & 10.90 & 7.54 & 81 & 1.90 & 3.72 & 2.45 \\
25 & 2.84 & 7.16 & 4.61 & 107 & 2.77 & 6.80 & 4.72 \\
27 & 3.28 & 9.68 & 6.36 & 109 & 1.39 & 2.61 & 1.74 \\
29 & 3.61 & 12.17 & 9.13 & 111 & 2.59 & 6.01 & 4.43 \\
31 & 3.45 & 10.89 & 7.36 & 113 & 1.99 & 3.98 & 2.27 \\
33 & 2.59 & 6.03 & 3.42 & Total & 3.80 & 13.97 & 9.60 \\
\hline
\end{tabular}


Tabla V. Resultados de la prueba de comparación entre dos grupos independientes No paramétrica de tipo Mann-Whitney para los indicadores de diversidad comunitaria del fitoplancton (Shannon y Números de Hill), considerando la escala temporal (día - noche) y espacial (costa - océano) en la CPC durante el crucero oceanográfico PACÍFICO XXXIX-ERFEN XXXVII, a bordo del ARC Providencia entre el 19 de septiembre y el 8 de octubre de 2004. Estaciones diurnas: 3, 5, 12, 29, 31, 43, 49, 107, 109, 113. Estaciones nocturnas: 1, 7, 10, 14, 16, 25, 27, 33, 45, 47, 75, 77, 79, 81, 111. Estaciones costeras: 1, 3, 5, 7, 10, 12, 14, 33. Estaciones oceánicas: 75, 77, 79, 81, 107, 109, 111, 113.

\begin{tabular}{|c|c|c|c|c|c|c|c|}
\hline \multicolumn{8}{|c|}{ A. Día- Noche } \\
\hline Fuente & N Día & N Noche & $\begin{array}{l}\text { Suma Ran- } \\
\text { gos Día }\end{array}$ & $\begin{array}{c}\text { Suma Rangos } \\
\text { Noche }\end{array}$ & U & Z & p-valor \\
\hline $\mathrm{H}^{\prime}$ & 15 & 10 & 186.5 & 138.5 & 66.5 & -0.47 & 0.6433 \\
\hline $\mathrm{N}_{1}$ & 15 & 10 & 187.0 & 138.0 & 67.0 & -0.44 & 0.6830 \\
\hline $\mathrm{N}_{2}$ & 15 & 10 & 189.0 & 136.0 & 69.0 & -0.33 & 0.7647 \\
\hline \multicolumn{8}{|c|}{ B. Costa - Océano } \\
\hline Fuente & N Día & N Noche & $\begin{array}{l}\text { Suma Ran- } \\
\text { gos Costa }\end{array}$ & $\begin{array}{l}\text { Suma Rangos } \\
\text { Océano }\end{array}$ & U & Z & p-valor \\
\hline $\mathrm{H}^{\prime}$ & 8 & 8 & 97.5 & 38.5 & 2.5 & 3.10 & 0.0006 \\
\hline $\mathrm{N}_{1}$ & 8 & 8 & 98.0 & 38.0 & 2.0 & 3.15 & 0.0006 \\
\hline $\mathrm{N}_{2}$ & 8 & 8 & 94.0 & 42.0 & 6.0 & 2.73 & 0.0005 \\
\hline
\end{tabular}

